\title{
The Digital Divide as a Complex and Dynamic Phenomenon
}

\author{
Jan van Dijk \\ Department of Communication, University of Twente, Enschede, The Netherlands
}

\section{Kenneth Hacker}

Department of Communication Studies, New Mexico State University, Las Cruces, New Mexico, USA

The purpose of this article is to propose a fruitful analytical framework for data supposedly related to the concept of the socalled "digital divide." The extent and the nature of this divide depend on the kind of access defined. Considering the possession of hardware, growing divides among different categories of income, employment, education, age, and ethnicity can be proved to have existed in the 1980s and 1990s according to official American and Dutch statistics. If only by effects of saturation, these gaps will more or less close. However, it is shown that differential access of skills and usage is likely to increase. The growth of a usage gap is projected. Multivariate analyses of Dutch official statistics reveal the striking effect of age and gender as compared to education. The usage gap is related to the evolution of the information and network society. Finally, policy perspectives are discussed.

Keywords access to information technology, digital divide, digital skills, information inequality, information society, knowledge gap, network society, policies of information equality, S-curve of adoption, usage gap, usage of information technology

\section{THE MULTIFACETED CONCEPT OF ACCESS}

There are heated debates occurring in the United States and in Europe concerning questions of whether there is a

Received 1 September 2000; accepted 1 August 2001.

Address correspondence to Prof. Dr. Jan A. G. M. van Dijk, University of Twente, Department of Communication, Institutenweg 1, Post Box 217, 7500 AE Enschede, The Netherlands. E-mail: J.vanDijk@ wmw.utwente.nl so-called "digital divide" and if there is, how important it might be. In turn, the question is whether it will close or widen in future years. Much of this discussion is politically charged. Old views reappear about markets and people who are supposed to solve all problems by themselves, or not, and about the need or rejection of government intervention. In this article we attempt to postpone this ideological discussion in order to develop scientific conceptual distinctions and to present reliable and valid empirical data of longitudinal research on this subject matter. The concepts of digital divide, access, adoption of innovations following $S$-curves, and so on are carefully explicated. The most reliable and valid data from the United States and European countries are summarized. Finally, some results of a large-scale official social survey in the Netherlands are presented, as it is one of the few that tried to go beyond the usual demographic background variables elaborating multiple regression models for the explanation of differences found in these background variables.

The first obstacle in research and discussion on information inequality is the multifaceted concept of access. It is used freely in everyday discussions without an acknowledgement of the fact that there are many divergent meanings in play. The meaning of simply having a computer and a network connection is the most common one in use today. However, according to Van Dijk (1999), this meaning only refers to the second of four successive kinds of access. He distinguishes four kinds of barriers to access and the type of access they restrict:

1. Lack of elementary digital experience caused by lack of interest, computer anxiety, and unattractiveness of the new technology ("mental access").

2. No possession of computers and network connections ("material access"). 
3. Lack of digital skills caused by insufficient userfriendliness and inadequate education or social support ("skills access").

4. Lack of significant usage opportunities ("usage access").

Clearly, public opinion and public policy are strongly preoccupied with the second kind of access. Many people think that the problem of information inequality in the use of digital technology or computer-mediated communication (CMC) is solved at the moment that everyone has the ability to obtain a personal computer and a connection to the Internet. The first kind of access problem, the mental barrier, is neglected or viewed as a temporary phenomenon touching only elderly people, some categories of housewives, illiterates, and the unemployed. The problem of inadequate digital skills is reduced to the skills of operation, managing hardware and software. Sometimes this is also viewed as a temporary phenomenon to be solved shortly after the purchase of a computer and a network connection. Differential usage of computers and network connections is also neglected as an important phenomenon. Because differential usage is presumed to be the free choice of citizens and consumers in a differentiating postmodern society, it has no been viewed as important to social and educational policies. Consequently, there is a strong material or "hardware orientation" approaching access to digital technology. We can see this in the most prevalent manner of framing the digital divide at this time.

According to Van Dijk (1999), access problems of digital technology gradually shift from the first two kinds of access to the last two kinds. When the problems of mental and material access have been solved, wholly or partly, the problems of structurally different skills and uses become more operative. Van Dijk (1999) does not limit the definition of digital skills to the abilities of operating computers and network connections only. Instead, he includes the abilities to search, select, process, and apply information from a superabundance of sources. In this way, he anticipates the appearance of a usage gap between parts of the population systematically using and benefiting from advanced digital technology and the more difficult applications for work and education, and other parts only using basic digital technologies for simple applications with a relatively large part being entertainment. Van Dijk stresses that computers and CMC are more multifunctional than previous communication technologies.

This position is elaborated in this article as further conceptual distinctions and the latest data presumed to be reliable and valid are described. We show that the digital divide is a very complex and dynamic phenomenon. As a result, it is not easy to explicate the most important tendencies and policy directions for this fairly new social problem. Yet we attempt to do this and also to suggest options for further research when knowledge and solutions are lacking.

\section{SOME FACTS: A DIGITAL DIVIDE IN THE UNITED STATES AND EUROPE?}

Unfortunately, most survey data about computer and Internet penetration or use are too unreliable and invalid to draw definite conclusions about the existence and development of digital divides. In particular, Internet statistics are notoriously unreliable for reasons of defective sampling or the nonresponse to and poor quality of much (marketing) telephone interviewing. Research would be improved with large surveys that have sufficient representativeness, or with census data and official government statistics. Further, to make statements and to test hypotheses about trends in computer or Internet penetration, it is necessary to have longitudinal or time-series data. These are rather rare, but they are beginning to appear now. From 1994 until 1999 we could use the biannual GVU surveys among Internet users (GVU Centre, Georgia University, 1994-1999). Time series could be constructed from their data. However, a major problem with these surveys is that they involve (self-)selective sampling.

Census material and other official statistics are starting to appear in the United States and Europe. The trends of the 1980s and 1990s, with 1998 and 2000 as the last years of measurement, can be derived from them. We base our conclusions on these data: the U.S. Census Bureau data of 1984, 1989, 1993, 1997, and 2000, the partly overlapping NTIA data about telephone and computer penetration for 1994, 1997, and 2000, and the annual Eurobarometer (European Union) and Dutch official statistics (by the SCP) of 1985, 1990, 1995, and 1998. The most important results of these official statistics in relationship to the four types of access distinguished are presented as sources of empirical research conducted by others. We do not present original data of our own.

\section{Elementary Digital Experience}

Few data are available - particularly in official statisticsconcerning the first experiences of potential users of digital technology. Mental barriers of access are neglected in the discussion about the digital divide. It is known that large segments of (even) the developed countries marked by high technology still have very little digital experience. Measuring the resulting digital skills (the ability to operate digital media and to search for information in them) one finds that even in one of the nations in Europe most equipped for digital communication, the Netherlands, $36 \%$ of the 1998 population had no or very few digital skills. Among people 65 years and older this figure reached $67 \%$ 
TABLE 1

Percentages of the population of computer users in the Netherlands in 1998, 18 years and older, with a particular score of digital skills in using 10 applications on a 1-5 scale: Windows, word processing in DOS and Windows, spreadsheets, drawing/graphics, working with keyboards, Internet, programming, e-mail, and statistical programs

\begin{tabular}{lccc}
\hline & $\begin{array}{c}\text { No or very } \\
\text { few skills, } \\
\text { score 1.0-2.0 }\end{array}$ & $\begin{array}{c}\text { Reasonable } \\
\text { skills, } \\
\text { score 2.1-3.5 }\end{array}$ & $\begin{array}{c}\text { Good skills, } \\
\text { score 3.6-5.0 }\end{array}$ \\
\hline $\begin{array}{l}\text { Total DUTCH } \\
\text { population of } \\
\text { computer users }\end{array}$ & 36 & 52 & 12 \\
Age & & & \\
18-34 years & 27 & 56 & 17 \\
35-49 years & 37 & 54 & 9 \\
50-64 years & 48 & 46 & 6 \\
65+ years & 67 & 31 & 2 \\
Gender & & & \\
Male & 28 & 55 & 17 \\
Female & 45 & 49 & 6 \\
Education & & & \\
Low education & 69 & 25 & 6 \\
Low middle & 49 & 46 & 5 \\
High middle & 30 & 58 & 12 \\
High education & 27 & 55 & 18 \\
\hline
\end{tabular}

Note. From representative GNC Survey reported in SCP (2000).

and among people with low education $69 \%$. The average of women with no skills was $45 \%$ and among people with low middle education it was $49 \%$ (see Table 1).

In another Dutch survey for digital skills, subjective and emotional factors appeared to be responsible for this lack of skills to a large degree (Doets \& Huisman, 1997). These factors entail experiences of personal shortcoming (leading to insecurity), of being excluded, and of negative attitudes toward this technology, all factors leading to so-called "computer anxiety." Such mental access problems become more important when it is claimed that there are not only information have-nots, but also information want-nots. Thus, there also are important motivational problems. In general, it appears to be possible to live and work without digital technology at the turn of the century. In 1999 a couple of European surveys were published revealing that about half of the population that was not connected to the Internet also did not want such a connection. One of these surveys was the German Online Nonusers Survey (ARD/ZDF, 1999a). Among the 501 nonusers in this representative sample for Germany, 234 (54\%) declared that they would not connect to the Internet for a variety of reasons of volition (see Figure 1).

The statements listed in Figure 1 reveal everyday reasons for not using the Internet, such as "I don't need it," "I don't like it, "I can't buy it," and "I can't handle it." Similar reasons were provided by households in the United States having a computer or WebTV in the year 2000 , but never using it to access the Internet (NTIA, 2000): "don't want" (31\%), "too expensive" (17\%), "can use it elsewhere" (10\%), and "no time" (9\%). Presumably, there are differences in motivations for using computers and the Internet among the populations of (even) high-tech countries. Older people, those with low education, a large proportion of women, and (functional) illiterates are strongly overrepresented among people with a lack of motivation (ARD/ZDF, 1999a; NTIA, 2000). Further research for the ingredients of the mixture of reasons observed here (anxiety, negative attitude, lack of motivation) is urgently needed.

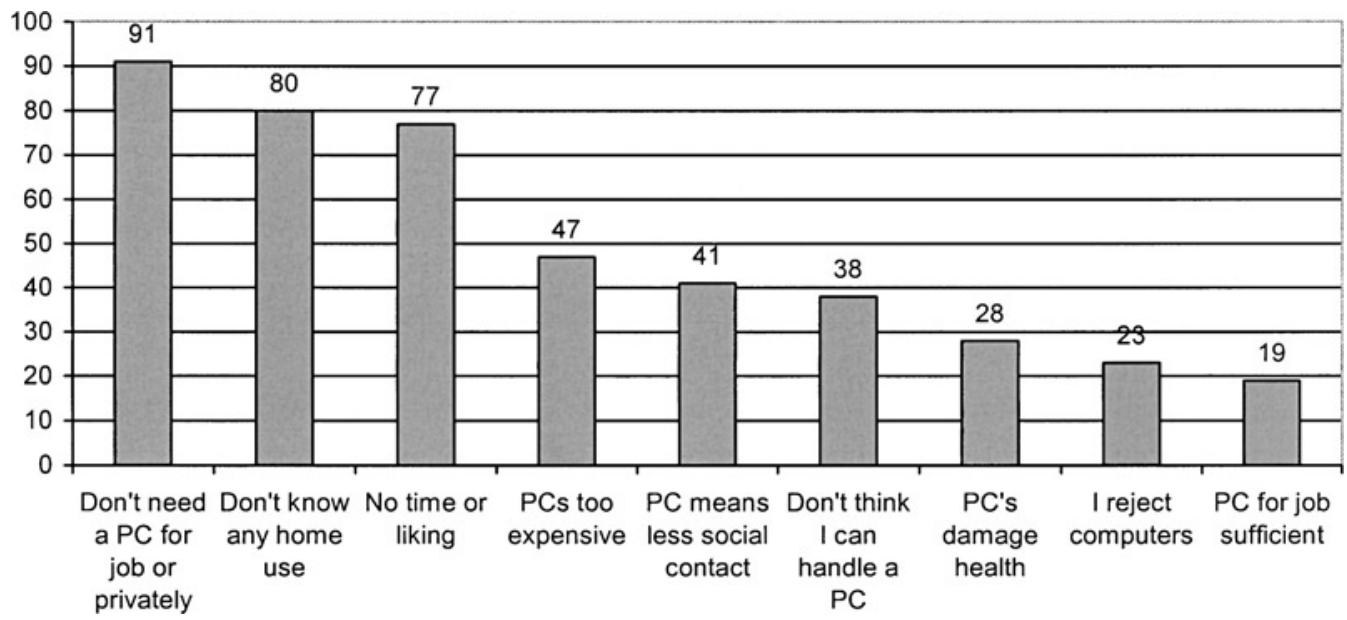

FIG. 1. Off-liners reasons for not buying a PC in Germany, 1999. From ARD/ZDF (1999a). 


\section{Possession of Computers and Network Connections}

Current discussions about the digital divide are dominated by the (lack of) universal availability of the hardware. Increasingly, longitudinal data in official statistics are being supplied. These data constitute strong evidence of gaps in the possession of computer and network connections among a number of social categories during the 1980s and 1990s: income, education, occupation, age, gender, ethnicity, and geographic location. By constructing time series from these data, it can be shown that most of these gaps of possession have increased during the 1980s and 1990s. Given next is a collection of figures showing this for the variables of income, education, and age in both the United States (see U.S. Census Bureau, 1984, 1989, 1993, 1997, 2000; Kominski \& Newburger, 1999) and the Netherlands (see SCP, 2000). Ethnicity is added as a category in the United States (Figure 2). Gender is not
GAP OF INCOME USA 1984-2000

HOUSEHOLD POSSESSION OF COMPUTERS

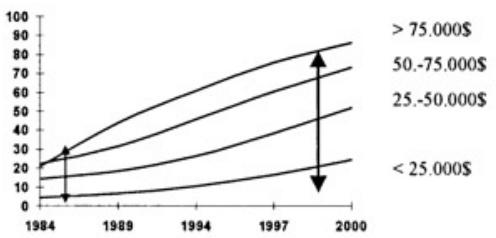

GAP OF EDUCATION (HEAD HOUSEHOLD) USA 1984-2000: HOUSEHOLD POSSESSION OF COMPUTERS

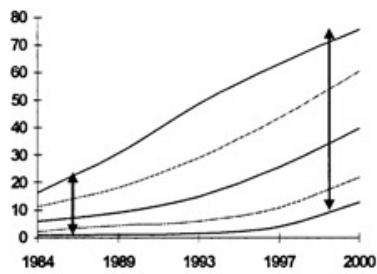

Bachelors

Some College

High School

Diploma

Some High S

Elementary

GAP OF AGE (HEAD HOUSEHOLD) USA 1984-1998 HOUSEHOLD POSSESSION OF COMPUTERS

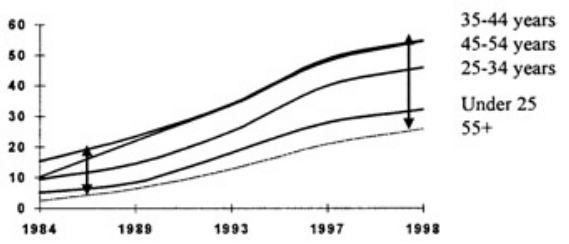

GAP OF INCOME NETHERLANDS 1985-1998 HOUSEHOLD POSSESSION OF COMPUTERS

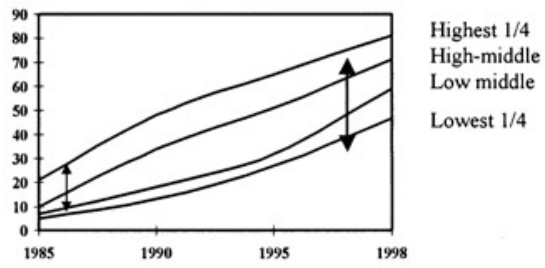

GAP OF EDUCATION NETHERLANDS 85-98 HOUSEHOLD POSSESSION OF COMPUTERS

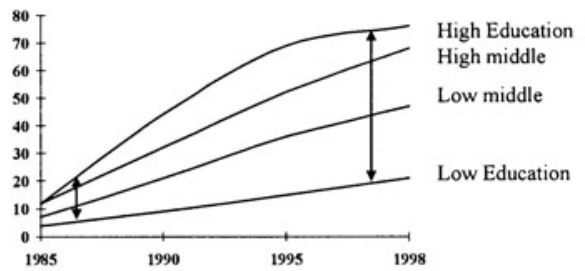

GAP OF AGE NETHERLANDS 85-98 HOUSEHOLD POSSESSION OF COMPUTERS

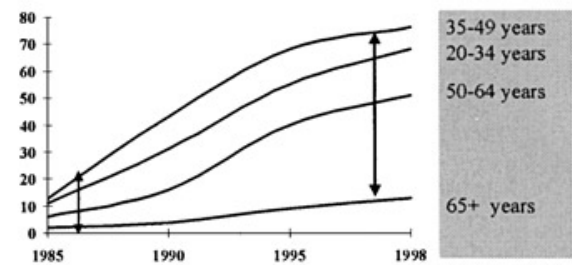

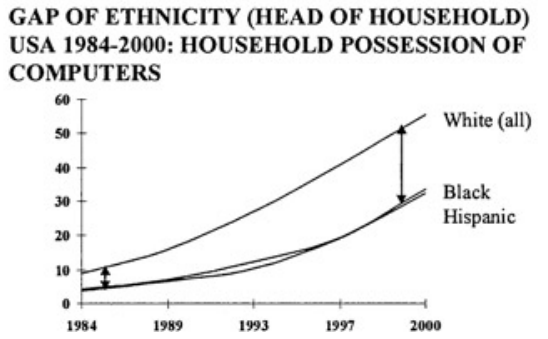

FIG. 2. (Left) Gaps of income, education, age, and ethnicity, in the United States, 1984-2000. Computed from U.S. Census Bureau data of 1984, 1989, 1993, 1997, 1998, and 2000, and data contained in NTIA (1999, 2000). (Right) Gaps of income, education, employment, and age, the Netherlands 1985-1998. From SCP (2000). 
included, because both sets of official statistics employed households as the unit of data collection. Gender differences related to possession of equipment are not sufficiently articulated in this type of research. They did appear significant in the biannual GVU surveys among individual web users (GVU Center, 1994-1999). However, it appears that the original gender gap in actually using PCs and the Internet decreased during the 1990s. In the year 2000 the gender difference in the possession of computers and the Internet and the time spent using them has been equalized in the United States (see NTIA, 2000). In the European Union (EU), women are still catching up (see the annual Eurobarometer surveys of the EU). However, it is important to emphasize that a gender gap concerning different skills and kinds of usage remains (see Tables 1, 2, and 3; Pew Internet, 2000).

The big question concerning the widening gaps is whether these trends will continue. From a statistical point of view, it is evident that they will not. Saturation of computer and network possession among the "higher" categories will set in, and presumably has already begun in countries like the United States and the Netherlands. For the "lower" categories there is much more room for catching up. Therefore, the question becomes how much current gaps will close in the first two decades of the 21st century. More importantly, we need to ask what kind of computers and network connections people will possess. We return to this crucial issue later.

Other important questions deal with the most important factors or variables among the familiar set of background variables. Evidently, income, education, and employment are strongly associated. Holding the other factors constant, it can be shown in the American and Dutch statistics that they keep an independent effect. The Dutch SCP study, however, employed elaborate multiple-regression analyses for the weight of the most important variables in the possession, skills, and use of information and communication technology (ICT). The results, summarized in Figure 3, are informative.

The most important conclusion from the 1998 Dutch SCP study is that household income is the most important factor explaining differences in the possession of ICTs, first of all PCs, and that income diminishes or even disappears in the explanation of differences in digital skills and ICT usage. Surprisingly high, perhaps, is the relative weight of age and gender. For age, the distribution is curved: First possession increases with age (with a top in the class of 30-40), and then it decreases. Women have significantly lower possession - in the EU, not in the United States-skills, and use of ICTs. We try later to explain why the possession of ICT is not only a matter of material resources but also of the attractiveness of this technology and the necessary skills to use it among people of different age and gender.

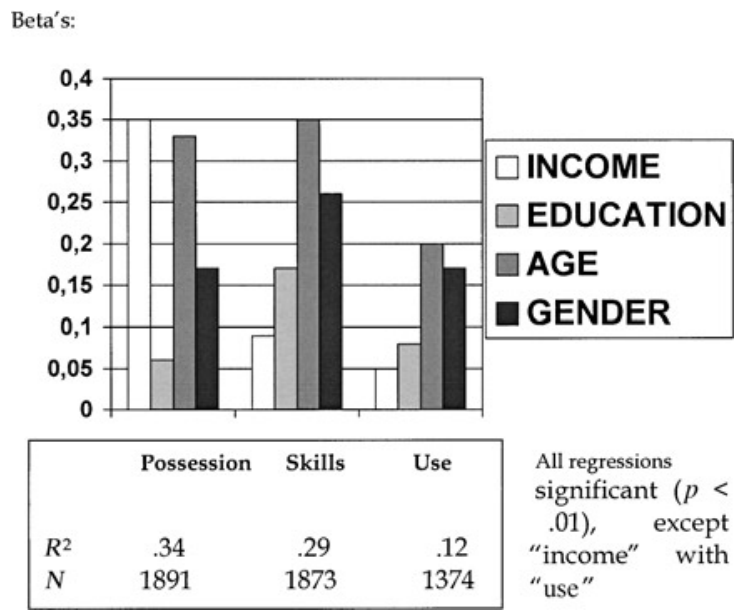

FIG. 3. A multiple regression comparing the relative significance of the variables of income, education, age, and gender in the possession, skills, and use of ICTs in the Netherlands in 1998. Data from representative GNC Survey 1998, SCP (2000).

\section{Digital Skills}

PCs and computer networks were renowned for their userunfriendliness until well into the 1990s. Major improvements were made with the introduction of graphical and audiovisual interfaces. However, the situation is still far from satisfactory if we look once again at Table 1 presenting differences of digital skills among social categories in the Netherlands. Gaps of digital skills can be shown to exist. The most common definition of digital skills is instrumental skills: the ability to operate hardware and software. In the study concerned, digital skills were operationalized using an index called "informacy" measuring both skills of operating digital equipment and skills of searching information using digital hardware and software. This means that so-called informational skills are added to the definition. We later recommend adding a third type of digital skills to the operational and informational ones: the strategic skills of using information for one's own purpose and position. Figure 3 reveals the (perhaps) surprising result that digital skills (instrumental and informational, together called "informacy" here) are not primarily related to educational levels but to age and gender. It is likely that this means that real practice and motivation are more important in acquiring digital skills than formal education. Indeed, many studies reveal that having computer experience at work, having particular hobbies, and having a family with schoolchildren are decisive factors in the acquisition of digital skills by adults.

\section{Different Uses}

In this article and in other publications (Van Dijk, 1997, 1999, 2000), it is predicted that different uses of ICT will 
TABLE 2

Usage of PC at home, United States, 1997

\begin{tabular}{|c|c|c|c|c|c|c|c|c|}
\hline & $\begin{array}{c}\text { Word } \\
\text { processing }\end{array}$ & Games & E-mail & Internet & Bookkeeping & $\begin{array}{l}\text { Work } \\
\text { at home }\end{array}$ & Spreadsheets & Databases \\
\hline $\begin{array}{l}\text { Total using PC } \\
\text { at home }\end{array}$ & 70.5 & 53.6 & 44.5 & 44.2 & 43.6 & 34.3 & 28.7 & 26.1 \\
\hline \multicolumn{9}{|l|}{ Age } \\
\hline $18-24$ years & 69.7 & 61.4 & 42.8 & 44.3 & 19.5 & 14.0 & 18.7 & 17.1 \\
\hline 25-49 years & 70.3 & 55.0 & 45.8 & 45.9 & 46.9 & 38.5 & 30.9 & 27.3 \\
\hline $50+$ years & 71.4 & 44.7 & 41.4 & 39.3 & 48.6 & 34.4 & 28.3 & 28.1 \\
\hline \multicolumn{9}{|l|}{ Gender } \\
\hline Male & 66.3 & 57.6 & 48.1 & 49.4 & 46.3 & 38.0 & 32.5 & 29.4 \\
\hline Female & 74.7 & 49.6 & 40.7 & 38.9 & 40.8 & 30.6 & 24.7 & 22.7 \\
\hline \multicolumn{9}{|l|}{ Family income } \\
\hline$<\$ 25,000$ & 69.1 & 57.2 & 40.6 & 38.9 & 35.5 & 22.7 & 22.3 & 20.9 \\
\hline$\$ 25-49,900$ & 66.2 & 58.4 & 39.7 & 39.8 & 43.7 & 29.2 & 25.3 & 23.9 \\
\hline$\$ 50-74,900$ & 71.2 & 55.4 & 44.9 & 45.1 & 43.9 & 35.5 & 29.7 & 26.7 \\
\hline$>\$ 75,000$ & 75.8 & 47.6 & 52.1 & 52.3 & 47.3 & 44.8 & 34.7 & 31.1 \\
\hline
\end{tabular}

Note. From U.S. Census Bureau data.

bring the most important digital and information inequalities in society. Presently, the differences observed in this kind of access are not as large as those in differential possession and skill.

Unfortunately, data about differential usage are still scarce and only a few years old. They are available for com- puter use and Internet use, both in the U.S. Census material and the Dutch SCP investigation. However, it is our view that only computer use has had enough time to crystallize; Internet use is only appearing as a mass phenomenon at the turn of the century. We must wait for longitudinal data to construct the time series we need for testing our

TABLE 3

General usage of PCs in the Netherlands, 1998

\begin{tabular}{lccccccc}
\hline & Word processing & Games & $\begin{array}{c}\text { CD-phone and } \\
\text { travel guide }\end{array}$ & $\begin{array}{c}\text { Spreadsheet/ } \\
\text { database }\end{array}$ & $\begin{array}{c}\text { Graphics/ } \\
\text { drawing }\end{array}$ & Internet & E-mail \\
\hline Total using PC at home & 86 & 59 & 46 & 45 & 37 & 37 & 34 \\
Age & & & & & & & \\
$\quad$ 18-34 years & 89 & 74 & 45 & 46 & 41 & 38 & 36 \\
35-49 years & 84 & 54 & 47 & 44 & 35 & 39 & 35 \\
50-64 years & 83 & 36 & 45 & 42 & 35 & 35 & 31 \\
$\quad$ 65+ years & 79 & 31 & 41 & 46 & 16 & 35 & 20 \\
Gender & & & & & & & \\
Male & 89 & 58 & 55 & 60 & 45 & 44 & 42 \\
Female & 81 & 60 & 32 & 36 & 26 & 27 & 25 \\
Family income & & & & & & & \\
1st Quartile & 90 & 74 & 42 & 43 & 42 & 33 & 30 \\
2nd Quartile & 82 & 62 & 47 & 40 & 36 & 31 & 28 \\
3rd Quartile & 85 & 57 & 45 & 39 & 36 & 37 & 35 \\
4th Quartile & 87 & 46 & 52 & 59 & 34 & 49 & 46 \\
Education & & & & & & & \\
$\quad$ Low education & 73 & 78 & 47 & 16 & 32 & 16 & 12 \\
Low middle & 72 & 66 & 42 & 32 & 38 & 32 & 29 \\
$\quad$ High middle & 88 & 64 & 43 & 45 & 36 & 35 & 32 \\
\hline
\end{tabular}

Note. From SCP (2000). 
prediction: the rise of a usage gap. Instead, we have to turn to data of single years like the state of affairs concerning computer use in the Netherlands and the United States, in 1998 and 1997, respectively, presented in Tables 2 and 3.

Here we can see substantial differences in the use of PC applications, especially among people with different levels of age, gender, and education. With age, fairly large differences appear in using games, spreadsheets/databases/ bookkeeping (United States), and drawing and e-mail use in the Netherlands. With gender we see that females use all applications significantly less than males. Levels of education appear to correlate with a different use of games, spreadsheets/databases, Internet, and e-mail (the Netherlands). In the United States only the data on income levels are available, revealing differences in e-mail and Internet use and other more advanced applications: bookkeeping, spreadsheets, databases, and work at home.

The latest Falling Through the Net study (NTIA, 2000) reveals important differences in Internet usage by income, education, ethnicity, and other variables, but unfortunately only informational, educational, and work-related types of Internet use were reported. It appears that with rising educational levels the Internet applications of information searching, doing job-related tasks, searching for jobs, and using e-mail increase significantly (see NTIA, 2000, Figure A49). On the other hand, people with lower education use the Internet relatively more to take courses. When we examine income these differences are less pronounced, supporting the SCP conclusion that income is less important than education considering usage (Figure 3). Taking courses and searching for jobs on the Internet is practiced more by Americans with low incomes than with high incomes in the year 2000. The same goes for unemployed Americans as compared to the employed (see NTIA, 2000, Figures A47 and A50). This reveals the importance of usage access and skills access compared to their necessary condition, material access. Having a computer and Internet connection and also having the skills to use them are becoming increasingly important resources on the labor market.

\section{INTERPRETATIONS}

As observed earlier, the data concerning the digital divide have come to constitute a political battlefield. Statistics are freely selected and judged according to political interests or subjective perspectives. Social and political opinion has developed four kinds of positions with an interpretation of current state of affairs:

1. Denial of the existence of a digital divide.

2. Acceptance of some present divides, claiming that they will soon disappear.

3. Emphasis of digital divides that are supposed to grow and come on top of old inequalities of income, education, age, gender, ethnicity, and geographical location.

4. Differentiation: some gaps are decreasing while others grow.

A number of market research institutions, other corporate interests, and conservative think tanks deny or trivialize the existence of digital divides. Basically, their arguments are threefold (see also U.S. Internet Council, 1999, based on Forrester research, and Thierer, 1999):

1. The adoption rate of computers and the Internet and the growth rates of their use are higher than any medium before, perhaps with the exception of (color) TV.

2. The distribution among the population approaches normality: The averages of income, education, ethnicity, and gender rapidly parallel society as a whole.

3. Computers and Internet connections are becoming cheaper by the day, cheaper than a color TV system adopted by almost every Western household. The market is doing its work and solves all problems.

Indeed, growth rates are enormous. However, there are some basic problems with the S-curve of adoption of innovations that usually is the basis of this argument. ${ }^{1}$ One of them is the demarcation problem of the media supposed to be entering an S-curve: A computer and an Internet connection now are very different from a computer and Internet connection 10 years ago. The new computer and Internet technologies are easier to use, but they have varying levels of complexity and options in hardware and software.

It goes without saying that a medium that is increasingly adopted into society is approaching average parts of the population. However, in our view digital divides are about relative differences between categories of people. In the 1980s and 1990s most of these divides concerning possession of computers and Internet connections have increased, as has been convincingly demonstrated by the American and Dutch official statistics supplied earlier. One is free to predict that these divides will close rapidly, an argument to be dealt with later, but their existence in the present and recent past cannot be denied. The argument about cheaper hardware is correct, but only partly so. It neglects many facts like:

1. The new media add to the older mass media that do not disappear: One still needs a TV, radio, VCR, telephone, and perhaps a newspaper; low-income households continually have to weigh every new purchase (with the newspaper beginning to lose).

2. Computers are outdated much faster than any other medium and new peripheral equipment and software continually have to be purchased. 
3. "Free" Internet access or computer hardware is not really free, of course. There are nominal monthly fees, long-term service agreements, privacy selling, and low-quality service, for instance.

However, the most important problem of this interpretation, and of the next one, is its hardware orientation. Perhaps the most common social and political opinion is that the problem of the digital divide is solved as soon as every citizen or inhabitant has the ability to obtain a personal computer and an Internet connection. In contrast, our analysis suggests that the biggest problems of information and communication inequality just start with the general diffusion of computers and network connections.

The second interpretation might accept that there are or have been gaps but asserts that they will soon disappear, perhaps to be succeeded by other inequalities. It is simply a question of some having the technology now and others having it later. The early adopters pay for the innovation and make the adoption cheaper for the late adopters. There is a strong faith in the trend of the S-curve of adoption and in the extension of access by market forces alone. This interpretation comes from the authors of the Dutch SCP survey, among others. From a statistical point of view their position will be backed by future data automatically. The saturation of possession by the "higher" social categories sets in, and has already started in some Western countries, as one can see in the slope of the top curves in Figure 2. This argument looks like a dynamic one because it accounts for trends into the future, but in fact it is static on several grounds. It reasons from present technologies and their uses. The issues are what relative differences will remain in 10-20 years and what kind of "computers" and "Internet" will be possessed. How will they be used? What skills will be needed? One has to remember that the comparable innovation of telephony took 70 years to acquire an (almost) general distribution and acknowledge that penetration rates are still not complete and that usage is very unequal, even in the rich developed countries. In the meantime, the next round of innovation in digital technology has already appeared: broadband or high-speed Internet access. It is striking to observe that the same divides in the possession of this technology among people with different income and education reappear, albeit in a mitigated form (see NTIA, 2000, Figures A18 and A19). This means that the differences between people with broadband and narrowband access are smaller than those between people with and without any access to computers and the Internet. Still, it is reasonable to say that all these differences work in accumulation and that the relative differences in hardware possession between people with different income and education, at least, are increasing.

Another argument of the disappearing gaps position is that there is no digital divide in the sense of a structural gap or a two-tiered society: The differences are of a gradual nature (see SCP, 2000). This qualification has some basis: The two-tiered position is too simple. The digital divide is a simplifying metaphor. In fact, we see the stretching of a whole spectrum of differentiating positions in (post)modern society, not two classes of people (Van Dijk, 1997, 2000). From a substantial point of view this qualification might also be right concerning the basic possession of computers and Internet connections, though the SCP survey's own conclusion is that household income is the most important factor explaining it. Yet we are not so sure that structural divides will disappear concerning digital skills and usage, the core of our argument.

The disappearing divide position often is politically motivated by the wish to prevent government interference. One supposes markets will solve most problems by themselves lowering prices and offering more choice to everybody and that people in their communities and organizations will solve the rest of problems in self-regulation. Rather than engaging in this ideological debate, we wish to draw attention to the straightforward fact that almost every government in the 20th century has adopted policies to promote important mass media for communication in society, including tax policies and hardware and support subsidies for all kinds of public services. We want to call attention to the fact that every government, including those committed to laissez-faire capitalism as in the United States, has implemented educational and cultural policies.

A third set of interpretations does emphasize the persistence and growth of a digital divide. It is supported by left-wing political forces, social democrats, socialists, progressive nongovernmental organizations (NGOs), etc. They stress the rise of social and economic inequality in Western society and on a world scale in general during the last two decades. They claim information inequality only adds another layer to increasing old inequalities of income, education, occupation or social class, ethnicity, and gender (see Schiller, 1996). They hold that the claim of cheaper information and communication technology (ICT) products is a corporate trick. After the relatively cheap supply of hardware access, the selling of expensive service and content starts. There may be large elements of truth in this interpretation: General inequality has increased both nationally and internationally (see United Nations Development Program, 1998), and old inequalities do not disappear with the advent of an information or knowledge society. However, this position underestimates the import and complexity of changes that are occurring. Increasing differences in the skill and usage of the new information technologies might lead to new inequalities of a nature not known before and to be combatted, if one chooses to do so, with other means than the traditional ones. Moreover, less expensive hardware with more capacity and free Internet access as a public service are very real and important 
phenomena. The new technologies offer new opportunities for citizen participation and the consumer interest.

The last set of interpretations stresses current differentiation in society in general and the use of ICTs in particular. Theoretical work on the information society or the network society sheds another light on social inequality (see Castells, 1996, 1998; Van Dijk, 1991, 1999, 2000). Others even claim that the information or knowledge society will discard old inequalities and bring completely new ones based on differential knowledge and education. Our analysis indicates that there also is continuity, as elaborated in the next section. Concerning the different divides discussed here, these interpretations stress that some current divides or gaps may (partly) disappear, while others stay or increase. This interpretation matches our conclusion that the current digital divide is a very complex and dynamic phenomenon. It is complex in the sense that, for example, access is a multifaceted concept with many types of problems, and it is dynamic in following the trends of evolving technology and its uses.

\section{SCIENTIFIC EXPLANATIONS}

The differences of possession, skill, and use of ICTs usually lack scientific explanation. Even multivariate analyses trying to weigh determining factors are rare. An exception is made by the Dutch SCP survey constructing regression models to explain these differences by unequal possession of resources by individuals or households. This is a classical sociological approach in empirical research. Three kinds of resources were distinguished: material, social, and cognitive resources. In this survey a very narrow definition of material resources appeared to explain more (in the regression models) than the usual variable in this respect: income. The variable constructed is narrow because it is only composed of questions about the possession of all kinds of equipment by households, albeit not only digital equipment. Social resources are made operational in a number of questions about (1) having a social network also possessing and using digital technology and (2) having social support in managing it. Cognitive resources are threefold: literacy, numeracy, and informacy. Literacy is the skill of reading and of searching information in texts. Numeracy is the ability to handle numbers, figures, and tables and to compute. Informacy is equal to digital skills in this survey. It is made operational in two ways: operating digital equipment, and searching for information in digital sources. The cognitive resources taken together appear to explain more than the variable of education.

The results of the regression model based on these resources are very interesting. Striking differences of the importance of these resources are found at the possession, skills, and use of ICTs, respectively (Figure 4). Possession of ICTs is explained more by informacy (instrumental and informational digital skills) than by material resources.

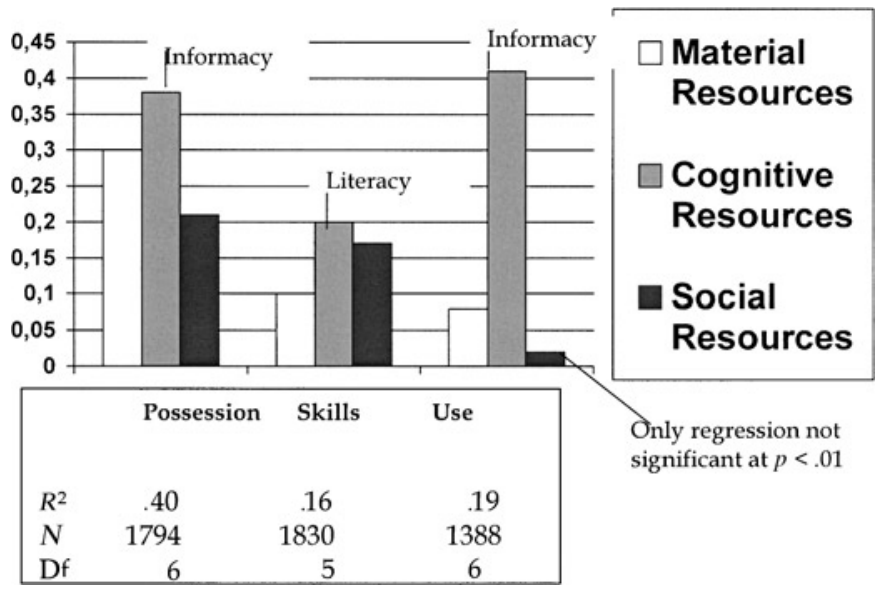

FIG. 4. A multiple regression comparing the relative significance of material, cognitive, and social resources in the possession, skills, and use of ICTs in the Netherlands in 1998. Data from representative GNC Survey 1998, SCP (2000).

Skills are explained by literacy and social resources (having a social network and support). A remarkable result is that literacy is far more important for the explanation of digital skills than numeracy. Apparently, people with the ability to process textual information are more likely to develop digital skills defined in this way than people that are good in numbers and computing. Clearly, computers are no longer only number crunching machines these days. Usage is overwhelmingly determined by informacy or digital skills.

The general conclusion of the SCP research team is that differences of skill and use are smaller than differences of possession. After the threshold of having a computer and network connection has been passed, material and social resources play a relatively minor role. Social-cultural differences of age, gender, literacy, and informacy come forward. Present differences and even divides are observedsee figures and tables already given - but according to the SCP team they are old inequalities that are reproduced, rather than new inequalities like the ones often related to a knowledge or information society. The team claims that there is no unbridgeable digital divide and that government intervention is not needed.

It is likely that these far-reaching political conclusions are drawn prematurely. They are based on a rather static and superficial sociological analysis of the present situation. Constructing rather arbitrary background variables of individual resources at a single point in time does not make a theory that is able to relate to social and technological development, that is to say, the level of society and technology. Technology is changing rapidly; very advanced and very simple applications are appearing side by side. And according to many scientists and other observers, society is evolving into an information society and a network society 
where social (in)equality will partly be different from old modern societies.

In an information society, information is known as a socalled primary good. Everybody needs it to function in society. However, people also need cultural capital (Bourdieu, 1986) and social capital (Mansell \& Wehn, 1998) to use information in appropriate ways - that is, the skills to select and process information and be able to use it in one's social position and network. These kinds of "capital" are distributed very unequally in society. Moreover, information is a positional good. This means that it becomes increasingly important to get the information first in economic, social, and cultural competition. This is why it is so important to look at the relative differences in all inequalities observed.

The importance of cultural and social capital for the ability to extract relevant information from innumerable sources and to use it for the benefit of one's position is even stronger in the network society, a typification in the line of the information society. A network society consists of social and media networks shaping the prime mode of organization and most important structures of modern society (Van Dijk, 1999). Here the position inside and outside networks becomes vital. This position defines one's opportunities and power in society. Remaining outside networks means total exclusion. Being inside might mean partial exclusion when the position occupied is a marginal one. The position acquired at work, at school, at home, and in the local community also determines the chances to acquire elementary digital experience, to develop further digital experience, and to use particular applications. Therefore we want to add a third type of digital skills to the instrumental and information skills already described: strategic skills, the ability to use digital means too improve one's position in society, in work, education, and cultural practices. This type of digital skill is closely related to the possession of social capital or social resources as defined earlier and it is the direct basis of usage access. In measuring social capital and resources, it is insufficient to observe only whether one is employed or not and how big ones household is. The precise positions at work (occupation, function, task), at school, in the family, and in the community have to be recorded and related to the possession, skills, and use of ICTs. Unfortunately, these data are scarce. We have seen that measuring skills and usage is a fairly recent research activity, particularly in relationship to the Internet. Thus, we are not able to look for such clear "gap pictures" as are available on the field of the possession of computers and network connections. The evidence is only fragmentary, like the tables of usage we supplied earlier, or it is too recent to construct time series, like the 1993 and 1997 U.S. Census Bureau statistics of the precise occupations and industries using particular applications of ICT (see U.S. Census Bureau, 1993, 1997).
Further research for the different kinds of digital skills and for usage is urgently required. This will allow us to investigate whether more or less structural inequalities in skills and usage appear between social classes and people of different age, gender, ethnicity, and geographical location. This is the hypothesis of simple versus advanced, businesslike versus entertainment applications adopted relatively more by particular classes of people, a suggestion made earlier.

Individual differences of ICT possession, skills, and use observed should not only be related to the general environment of the information or network society, but also to the particular social trends of a particular epoch. Van Dijk (1999; pp. 153-154) has argued that in the present epoch several trends come together to promote information inequality: social and cultural differentiation or individualization, rising income differentials, privatization and cutbacks in social and public services, and, finally, increasingly multifunctional and differently used digital technology. The last trend supports Van Dijk's vision of the new media as trend amplifiers: Equalities and inequalities already present, growing or declining in society will be reinforced by this technology.

\section{CONCLUSIONS AND POLICY PERSPECTIVES}

Following the line of the argument in this article, the complexity of the picture of the so-called digital divide comes to our mind. A number of significant gaps have been observed and supported by relatively reliable official statistics and surveys. However, there is no question of an absolute, yawning and unbridgeable gap between two classes of people. Talk about "technological segregation" (NAACP President Kweisi Mfume) and "classical apartheid" (Reverend Jesse Jackson) is exaggerated and misses the point. The point is that the gaps observed show first of all relative and gradual differences. This makes them no less important. In the information and network society, relative differences in getting information and lines of communication become decisive for one's position in society, more than in every society in history before. Giving everybody a computer and a network connection, banning the cutting lines of "segregation" in this way, will not remove them. Much deeper and more clear-cut differences in skill and usage will appear as both technology and society increasingly differentiate. The fundamental task of future society will be to prevent structural inequalities in the skill and usage of ICTs from becoming more intense. Inequalities become structural when they "solidify," that is, when positions people occupy in society, in social networks, and in media networks, or other media, become lasting and determine to a large degree whether they have any influence on decisions made in several fields of society. 
Another reason for the complexity of the digital divide is that there are in fact several divides. Some are widening while others are closing. Time series of official statistics have demonstrated that during the 1980s and 1990s gaps of income, education, age, and ethnicity in the possession of computers and hardware have grown, at least in the United States and the Netherlands. Clearly, the people at the "better side" of these gaps have increased their lead during these decades. Though these gaps of possession will (at least partially) close in the next decades, if only for the statistical reason of saturation effects, it is very unlikely that those having acquired a big advantage will stop and lean backward. Technology is advancing, splitting in simple and highly evolved applications, spreading into society and sticking to old and new social differences.

In the course of the 1990s the gender gap in the possession of ICTs has started to close. However, gender gaps in skill and usage remain or mature, though they are much smaller for girls and boys than for adults (see GVU, 19941999; ARD/ZDF, 1999b; SCP, 2000; Pew Internet, 2000).

Large differences in digital skill and usage have been observed recently. Here gaps might grow in the future, although this cannot be proven at this moment due to a lack of time-series data.

The conclusions just described have also highlighted the dynamic nature of every digital divide. One should not stop at a particular point in time and say that a particular technology or application will be available to everybody within a couple of years or at any projected date in the future. Information and communication technology will differentiate considerably in the first decades of the 21 st century. Computers will be available in the simplest (palm-top and other) forms and very advanced types of desktops, laptops, and servers. "The Internet" will be accessible via televisions, mobile phones, and other small information appliances next to fast broadband connections. An important policy question will be whether palm-top computers and mobile phones or all kinds of narrowband access will be sufficient to be called the basic connection every citizen needs. Moreover, what does basic access to the Internet mean: both at home and at work/school, or is one of them sufficient, or perhaps even a connection in a public utility?

An important characteristic of ICT in this respect is its extended multifunctionality. Printed media, radio, television, and telephone have all been used differently by people with high and low education in particular. However, their (difference in) functionality is small compared to computers and the Internet. In the meantime, society is also differentiating at an unprecedented scale. Together those may create a usage gap that is somewhat similar to the knowledge gap described by Tichenor et al. a long time ago. "As the diffusion of mass media information into a social system increases, segments of the population with a higher socio-economic status tend to acquire this information at a faster rate than the lower status segments" (Tichenor et al., 1970, p. 159).

Although the evidence in favor of the thesis of knowledge gap has not been conclusive (Gaziano, 1987), it might get another chance in the information or network society where information is a positional good. We propose to relate this gap to a usage gap, not primarily based on differential derived knowledge or information but on differential practical use and positions in society.

The policy perspectives to be linked to this analysis clearly depend on one's central objectives concerning information inequality and one's political position. Central objectives might be twofold. The most basic one is social inclusion. A step further is made in the objective of an equal distribution of resources or life chances. The first objective is backed by a coalition of forces in advanced high-tech societies. Corporations look for a large electronic marketplace. Politicians want extended reach for political persuasion and a grip on new channels of political communication bypassing traditional mass media. Military people and security agencies want everybody to be connected for purposes of control and surveillance, as the off-liners of the future will create unknown risks. Educators are concerned about universal and public access to all learning resources. Community builders want every citizen to be involved in online communications linked to offline local activities.

The second objective is more traditional and it is supported more in Europe than in the United States, for instance. The minimum is an equal distribution of chances to every individual, an objective also having a broad support. Filling in what this means for actual material, social, and cognitive resources reveals the differences of political position.

Policy perspectives should be linked to the four kinds of access that have been distinguished. Governments, civil societies, and markets all have important roles to play in the support of these kinds of access.

Elementary digital experience is first of all a question of the market developing and offering ICTs that really are user-friendly and that offer such a clear surplus value as compared to old applications that the "information wantnots" will be convinced. Even at that point, many elderly and less educated people and some categories of housewives will stay behind. This will be the most important mission of adult education to be offered by governments, community centers, and corporate training.

Concerning the general possession of computers and networks, markets have done a good job lowering prices for technologies with higher capacities. However, this has not prevented the growth of digital divides in the possession of hardware, at least until very recently. Household income is still the most important factor here. Thus, tax 
and income policies of governments certainly do make sense. However, general tax credits or subsidies are not effective. They have to be focused on the groups clearly staying behind, all of them in the lowest quarter of the income distribution. A second qualification is the need of public or private service and guidance. Simply offering cheap boxes with computers and Internet connections makes little sense in this situation.

Learning digital skills will be a strategic objective for educational institutions at all levels. The official American and Dutch surveys cited in this article indicate that present digital skills are learned more at work than at schools or at home. In general, formal education runs behind because means are lacking and teachers are not sufficiently trained or motivated. Filling in this strategic objective, it will become evident that digital skills not only mean abilities to operate the hardware and software (instrumental skills). Increasingly, they will mean the ability to search, select, process, and apply information (informational skills) from digital sources and to strategically use them to improve one's position in society (strategic skills). At least instrumental and informational skills have to be learned at schools.

Improving usage opportunities for all means making them more attractive to some people in the first place. We have observed the surprisingly high independent effects of age, gender, and ethnicity (in the United States) for the actual use of ICTs. Applications should be made more attractive to many old people, women, and ethnic minorities. This is a matter of design, culture, language, and identity included and addressed in the applications concerned. Producers, designers, and representatives of citizens and consumers have a job here.

\section{NOTE}

1. The S-curve of the adoption of innovations presupposes that the medium in question is easy to identify and to mark from others. This might be true for older mass media like a radio, a TV, or a VCR, but not for computers and network connections. They fall apart in extremely different types, strongly complicating the construction of any valid time series of adoption. The second questionable proposition is the maximum population of potential adoption. The classical S-curve presupposes whole populations. However, some new computer and network media are too advanced, complicated, and expensive to be ever adopted by $100 \%$ of the population.

\section{REFERENCES}

ARD/ZDF-Arbeitsgruppe Multimedia. 1999a. ARD/ZDF Online Studie 1999. Media Perspektiven 8/99:388-409.

ARD/ZDF-Arbeitsgruppe Multimedia. 1999b. Internet-(K)eine Männerdomäne. Media Perspektiven 8/99:423-429.

Bourdieu, P. 1986. The forms of capital. In Handbook of theory and research for the sociology of education, ed. John R. Richardson, pp. 241-258. New York: Greenwood Press.
Castells, Manuel. 1996. The information age: Economy, society and culture, Vol. I: The rise of the network society. Cambridge, MA: Blackwell.

Castells, Manuel. 1998. The information age: Economy, society and culture, Vol. III: End of millennium. Malden, MA: Blackwell.

Doets, Cees, and Huisman, T. 1997. Digital skills. The state of the art in the Netherlands. 's-Hertogenbosch: CINOP. 〈http://www.cinop.nl〉 (English summary).

Gaziano, C. 1987. The knowledge gap: An analytical review of media effects. Communication Research 10:447-486.

GVU Centre, Georgia University. 1994-1999. GVU's 1st-10th WWW User Surveys. 〈http://www.gvu.gatech.edu/user_surveys/〉

Kominski, R., and Newburger, E. 1999. Access denied: Changes in computer ownership and use: 1984-1997. Paper presented at the Annual Meeting of the American Sociological Association, August, Chicago.

Mansell, Robin, and Wehn, U. eds. 1998. Knowledge societies, Information technology for sustainable development. Oxford: Oxford University Press.

NTIA (U.S. Department of Commerce). 1999. Falling through the Net III: Defining the digital divide. (http://www.ntia.doc.gov/ ntiahome/fttn99/part1.html $>$

NTIA (U.S. Department of Commerce). 2000. Falling through the Net IV: Towards digital inclusion. 〈http://www.ntia.doc.gov/ ntiahome/fttn00/contents00.html $>$

Pew Internet \& American Life Project. 2000. Tracking online Life: How women use the Internet to cultivate relationships with family and friends. Washington, DC: PEW. 〈www.pewinternet.org)

SCP (Sociaal-Cultureel Planbureau/Social-Cultural Planning Agency), Van Dijk, Liset, J. de Haan, and Rijken, S. 2000. Digitalisering van de Leefwereld, een onderzoek naar informatie en communicatietechnologie en sociale ongelijkheid. Contains a summary in English. Rijswijk, the Netherlands: SCP.

Schiller, Herbert. 1996. Information inequality. The deepening social crisis in America. New York: Routledge.

Thierer, A. 2000. How free computers are filling the digital divide. Heritage Foundation Backgrounder 1361, 20 April. 〈http://www. heritage.org $\rangle$

Tichenor, P. J., and Donohue, G., and Olien, C. 1970. Mass media flow and differential growth in knowledge. Public Opinion Quarterly 34:159-170.

United Nations Development Program. (1998). Human development report 1998. New York: Oxford University Press.

U.S. Census Bureau. 1984, 1989, 1993, 1997, 1998, 2000. Current population surveys. Washington, DC: U.S. Census Bureau.

U.S. Internet Council. 1999. State of the Internet: USIC's report on use \& threats in 1999. 〈htpp://www.usic.org/usic_state_of_net99.htm〉

Van Dijk, J. A. G. M. 1991. De Netwerkmaatschappij, Sociale aspecten van nieuwe media. Houten, the Netherlands: Bohn Stafleu van Loghum.

Van Dijk, Jan A. G. M. 1997. Universal service from the perspective of consumers and citizens, Report to the Information Society Forum. Brussels: European Commission/ISPO.

Van Dijk, Jan. 1999. The network society, Social aspects of new media. Thousand Oaks, CA: Sage.

Van Dijk, Jan. 2000. Widening information gaps and policies of prevention. In Digital democracy, Issues of theory and practice, eds. K. Hacker and J. Van Dijk, pp. 166-183. Thousand Oaks, CA: Sage. 
Copyright $\odot 2003$ EBSCO Publishing 
Copyright $\odot 2003$ EBSCO Publishing 